\title{
Hypothyroidism with hypertrichosis, polycystic ovaries and pituitary adenoma
}

\author{
Partha Pratim Halder $^{1}$, Apurba Ghosh ${ }^{1}$, Moutusi Raychaudhuri ${ }^{2}$
}

Sri Lanka Journal of Child Health, 2012; 42(3): 168-169

(Key words: Hypothyroidism; hypertrichosis; ovarian cyst; pituitary adenoma)

\section{Case report}

A 6 year old girl was referred for assessment with a history of poor growth for about three years, with gradually increasing dryness of skin, lethargy and growth of body hair over the previous six months. On examination she had dry skin with cold extremities. Hypertrichosis was particularly noticeable over the lateral aspects of the limbs, the forehead and the back (Figure 1).

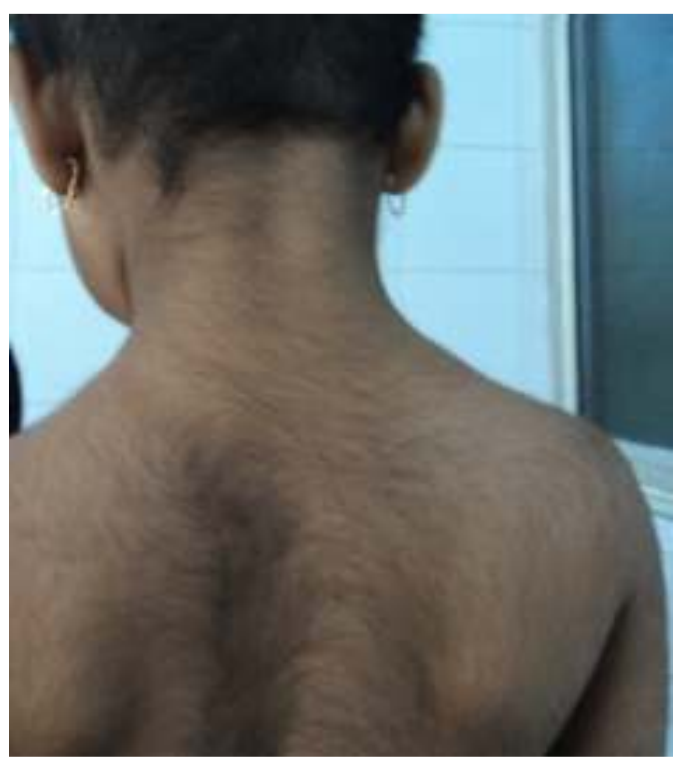

Figure 1: Hypertrichosis of back

She had Tanner stage 1 pubic hair with stage 1 breasts and axillary hair ${ }^{3}$ and normal female external genitalia. Standing height was $110 \mathrm{~cm}$ $\left(10^{\text {th }}\right.$ to $25^{\text {th }}$ centile $)$ and weight was $18 \mathrm{~kg}\left(10^{\text {th }}\right.$ to $25^{\text {th }}$ centile) with normal body proportions. Blood pressure was $80 / 46 \mathrm{~mm} \mathrm{Hg}$. Tendon reflexes were normal. Skinfold thickness at triceps and subscapular sites were $25^{\text {th }}$ and $50^{\text {th }}$ centile, respectively.

${ }^{1}$ Department of Paediatric Medicine, ${ }^{2}$ Department of Paediatric Endocrinology, Institute of Child Health, Kolkata-17, India

(Received on 9 October 2012: Accepted after revision on 16 November 2012)
Investigations showed normal diurnal cortisol, oestradiol, testosterone, dehydroepiandrosterone, androstenedione prolactin, $17 \alpha$ hydroxyl progesterone and sex hormone binding globulin concentrations. Basal thyroxine and thyroid stimulating hormone levels were $0.6 \mathrm{ng} / \mathrm{L}$ (Normal $0.8-1.8 \mathrm{ng} / \mathrm{L}$ ) and $146 \mu \mathrm{IU} / \mathrm{ml}$ (Normal 0.5-4.7 $\mu \mathrm{IU} / \mathrm{ml}$ ) respectively. Karyotype was $46 \mathrm{XX}$. Bone age was 4 years at a chronological age of 6 years. An x-ray film of the skull suggested rounding of the sella turcica. Magnetic resonance imaging (MRI) of brain showed pituitary adenoma (Figure 2).

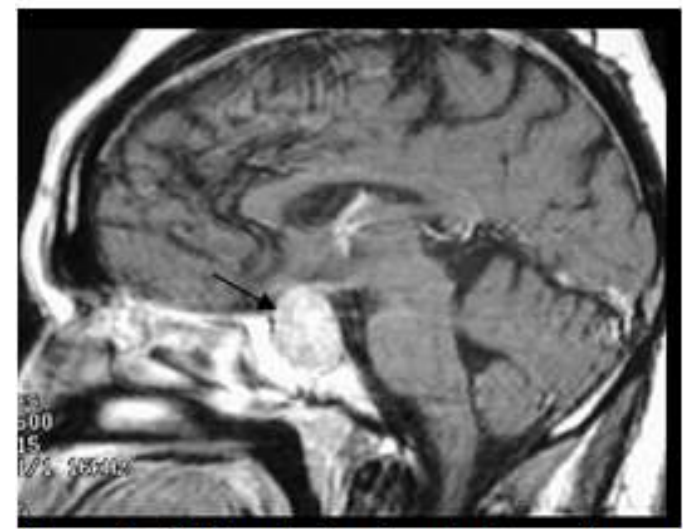

Figure 2: MRI brain showing pituitary adenoma

Anti TPO antibody level was $223.05 \mathrm{IU} / \mathrm{ml}$ (Normal $<5.61 \mathrm{IU} / \mathrm{ml}$ ) and anti-thyroglobulin level was 135.17 (Normal $<4.17 \quad \mathrm{IU} / \mathrm{ml}$ ). Thyroid scintigraphy showed poor and patchy uptake of radiotracer suggestive of subacute thyroiditis (Figure 3).

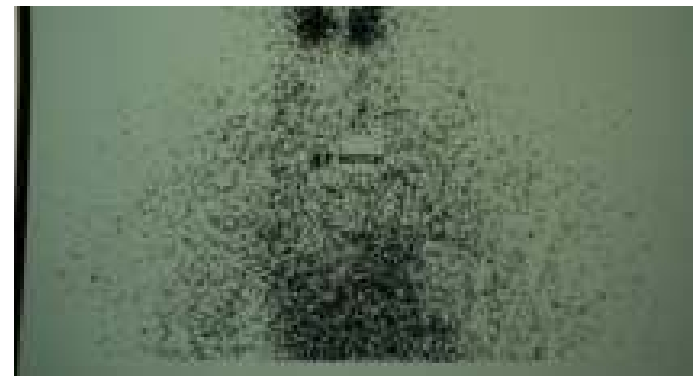

Figure 3: Thyroid scintigraphy 
Ultrasonography of abdomen showed bilateral ovarian cysts (Figure 4).

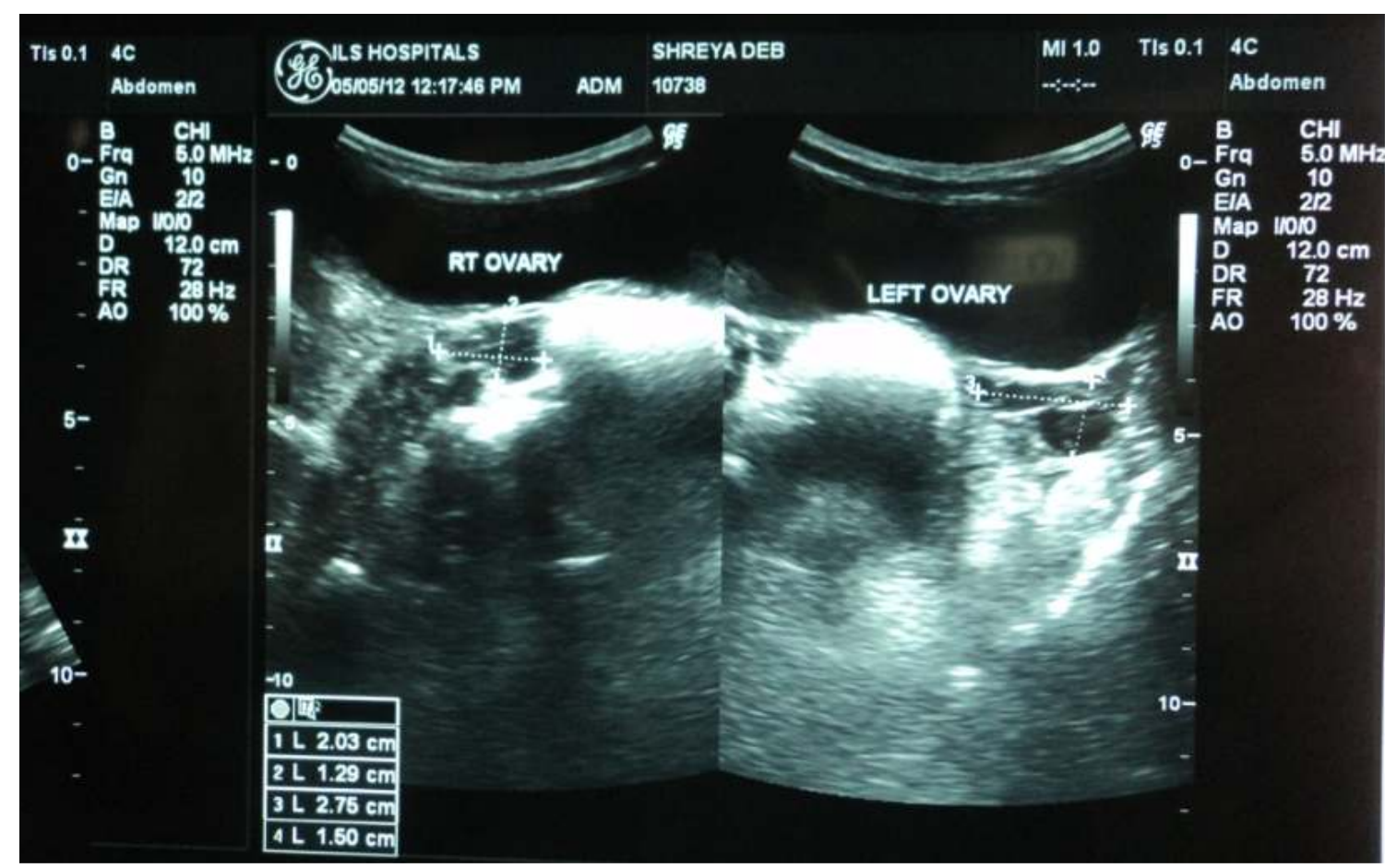

Figure 4: Ultrasonography of abdomen showing bilateral ovarian cysts

Hirsutism as a manifestation of juvenile hypothyroidism has been described by Perloff ${ }^{1}$. Multicystic ovaries in young girls with primary hypothyroidism have been described earlier ${ }^{2}$. Pituitary enlargement in primary hypothyroidism, too, is a known entity ${ }^{3,4}$.

\section{References}

1. Perloff WH. Hirsutism: a manifestation of juvenile hypothyroidism. Journal of the American Medical Association 1955; 157:6512.

http://dx.doi.org/10.1001/jama.1955.02950250 $\underline{025006}$

2. Sanjeevaiah AR, Sanjay S, Deepak T, Sharada A, Srikanta SS Precocious puberty and large multicystic ovaries in young girls with primary hypothyroidism. Endocrine Practice 2007; 13(6):652-5

http://dx.doi.org/10.4158/EP.13.6.652

3. Agrawal A, Diwan SK. Pituitary hyperplasia resulting from primary hypothyroidism. Asian Journal of Neurosurgery 2011; 6(2): 99-100. http://dx.doi.org/10.4103/1793-5482.92171

4. Khawaja NM, Taher BM, Barham ME, Naser AA, Hadidy AM, Ahmad AT, et al. Pituitary enlargement in patients with primary hypothyroidism. Endocrine Practice 2006; 12(1):29-34

http://dx.doi.org/10.4158/EP.12.1.29 